\title{
CIRCULATION, MONUMENTS, AND THE POLITICS OF TRANSMISSION IN SIR WALTER SCOTT'S TALES OF MY LANDLORD
}

\section{BY KYOKO TAKANASHI}

In the opening passage of Sir Walter Scott's The Heart of Midlothian, the narrator, Peter Pattieson, asserts that the "times have changed in nothing more . . . than in the rapid conveyance of intelligence and communication betwixt one part of Scotland and another." Pattieson seems to confirm the crucial role that the speed of print distribution played in Romantic print culture, particularly in relation to time-sensitive reading material such as periodical publications, political pamphlets, and statements by various corresponding societies. ${ }^{2}$ Indeed, the rapidity of the mail-coach that enabled up-to-date communication seems crucial to our understanding of the Romantic period as an age that became particularly cognizant of history as an ongoing process, forming, as it were, what Benedict Anderson characterizes as a "historically clocked, imagined community."3 And yet the first half of Pattieson's sentence reveals ambivalence about such change; while he admits that there has been dramatic increase in the speed of communication, he also asserts that "nothing more" has changed. Despite the presence of "the new coach, lately established on our road," Pattieson considers the village of Gandercleugh as otherwise unchanged, since it still offers him the opportunity to collect local, historical tales that will eventually be published as Tales of My Landlord $(H, 14)$. This representation of communication infrastructures in Tales of $M y$ Landlord series does not so much confirm the thorough penetration of a national print-based imagined community as it exposes how this national infrastructure existed uneasily alongside pockets of traditional, local communities.

Time and time again, Scott has been accused of manipulating his representations of Scotland and its people in ways that cater to the mainstream-that is, English-reading public. Such accusations have started to appear soon after the first publication of his novels when, as Ina Ferris details, some of Scott's contemporaries objected to his depiction of Covenanters in Old Mortality. ${ }^{4}$ The accusations continue to this day as critics argue that Scott essentially commodifies Scotland 
for the consumption of English readers in his historical novels. ${ }^{5}$ Rather than adding to these accusations, this article draws attention to the way Scott attempts to create an alibi, an excuse in his novels for these unsatisfactory representations. The opening passage to The Heart of Midlothian that I mention above, exemplifies Scott's own sense of the contradiction inherent in taking a historical narrative transmitted within a particular local community and circulating it throughout the nation. In the following discussion of Old Mortality and The Heart of Midlothian, I examine how Scott attempts to negotiate and bridge the gap between isolated local communities and a print-based imagined community by theorizing narrative transmission within his frame narratives. For Scott, the national imagined community, which continues to extend its reach as roads are built and mail-coach routes are instituted, does not so much incorporate localities into a national network of communication as subordinate them. This subordination has dire consequences for the literary health of the nation, since the national print market brainwashes readers with mass-produced narratives that merely reproduce conventional patterns, while authentic historical narratives remain entrapped within individual local communities. In the first two installments of Tales of My Landlord series, Scott explores how an authentic historical narrative might be recovered from obscurity and put into national circulation without losing its authenticity. This exploration results in a series of renegotiations-between circulation and stability, between reproductions and originals, between spatial and temporal transmission-that help to establish a modern conception of literary value that lays the groundwork for institutionalizing the English novel.

\section{NEGOTIATING SPACE AND TIME: TRANSMITTING TALES OF MY LANDLORD}

In the introduction to Old Mortality, Jedediah Cleishbotham, the fictitious editor of Tales of My Landlord, presents himself as an armchair traveler. Having spent the last forty years sitting "in the leathern armchair, on the left-hand side of the fire, in the common room of the Wallace Inn, winter and summer, for every evening in my life," Cleishbotham claims that he has "seen more of the manners and customs of various tribes and people, than if [he] had sought them out by [his] own painful travel and bodily labour." ${ }^{\prime 6}$ For Cleishbotham, the centrally located town of Gandercleugh is also the center of information. He presumes that the knowledge of the world will be gained efficiently by remaining stationary like the "tollman at the well-frequented turnpike" 
$(O, 6)$. Circulation may put people, things, and information in motion, but Cleishbotham asserts that individuals may benefit from the effects of circulation if they place themselves in a privileged - that is, central-position to observe and to gather information. In doing so, he reverses the logic of cultural capital represented in eighteenth-century novels of social circulation in which protagonists gain experience by circulating throughout the nation and exchanging narratives with various characters like innkeepers. ${ }^{7}$ Cleishbotham suggests instead that an innkeeper has as much claim to knowledge of the world as the customers he serves. He asserts that sitting still at the Wallace Inn contributes to the "enlargement of my views of the ways and works of the present generation" $(O, 5)$ - a qualification that, in his opinion, demonstrates his capacity to write novels like the following narrative of Old Mortality, which he "could have written ... if [he] would" $(O, 9)$.

Cleishbotham's claims about his superior knowledge of the world, however, expose his misrecognition of genre. His introduction underscores how oblivious he is to the contents of the following narrative. The plot of Old Mortality revolves around the seventeenth-century struggles between the Covenanters and the Loyalists, culminating in the battle of Bothwell. The novel follows the vicissitudes of the hero, Henry Morton, who becomes part of the Covenanters' army from circumstances rather than from choice. Much of the succeeding narrative revolves around the precarious position that Morton holds within the Covenanters' army, and the fates of the various characters as they experience the shifting political alliances brought about by the Glorious Revolution. Cleishbotham claims that he could have written this narrative because he has sufficient knowledge of the world today, but that would hardly seem to help him write a historical novel that narrates these events that occurred more than a century ago. The criteria that Cleishbotham uses to establish his ability to write such a narrative is based upon the precedence of writers such as Henry Fielding, who claims that an author needs "[a] true knowledge of the world [that] is gained only by conversation." It is not that Fielding's claim is outdated. Novels of manners may continue to depict the manners of the present time, but the historical novelist, whose characters are clothed in garbs of past generations, must look beyond manners and describe "those passions common to men in all stages of society."

Cleishbotham fails to assess the genre of the tale he introduces because he does not understand the relationship between genre and circulation. The novel of manners gathers its material from the realm of social circulation; it capitalizes on people who circulate in 
the fashionable world, their dresses and knick-knacks that circulate as commodities, and their stories that circulate in the form of gossip and "that part of a newspaper entitled the Mirror of Fashion." ${ }^{10}$ Gathering such objects in the amusing form of narrative, novels of manners place them back into the realm of circulation through the print market so that the world they represent and the world they inhabit reciprocally inform one another. Such, however, is not the case with Old Mortality. This historical narrative does not take its ingredients from the world of circulation, but from history, and its relationship to circulation differs from that of novels of manners. Historical novels circulate in the print market like novels of manners or periodicals, but they do not gather their materials from the synchronic realm of economic circulation. Cleishbotham himself gestures towards two distinct functions of circulation when he states that travelers at Wallace Inn would tell "news that had been gathered in foreign lands, or preserved from oblivion in this our town" $(O, 8)$. Here he identifies two distinct functions of circulation - gathering and preserving. While he attempts to establish his authority based upon the former function of circulation, the narrative that follows his introduction works upon the latter principle of preserving stories that may otherwise remain in oblivion. Cleishbotham overlooks this latter function of circulation not only because he is too busy asserting his cultural authority, but also because he is not the real author of the historical narrative. The reader finds in the two final pages of Cleishbotham's introduction that the Tales were not written by him, but by his deceased employee and Gandercleugh school teacher, Peter Pattieson, whose "papers have been left in [his] care" $(O, 9)$. It is Pattieson, then, and not Cleisbotham, who is responsible for preserving the following historical tale from oblivion.

The introduction to Old Mortality dramatizes the intersection between temporal and spatial transmission so as to situate the genre of the historical novel at the juncture of an isolated local community where historical narratives remain buried in oblivion and an information economy that extends far and wide. Although Cleishbotham mistakes the nature of his agency, he nevertheless participates in a cultural mechanism that preserves local history through the functions of modern circulation. By the Romantic period, writers and readers were already able to assume that literature-and poetry in particular-had powers of preservation. William Wordsworth, for instance, was able to envision his poetry as a vehicle that could "summon back from lonesome banishment" the "plenteous store" of "yet remembered names" and "make them inmates in the hearts of men / Now living, or to live in 
times to come."11 Rather than following Wordsworth's lead and taking it for granted that it is the nature of literature to withstand the corrupting and obscuring forces of time, Scott labors, first of all, to situate his text within a process that enables literary texts to preserve obscure narratives in the first place. In the succeeding pages of Old Mortality, Scott proceeds to outline such a process of preservation by staging the origin of the narrative within a communal network of transmission that preserves the narratives of the dead. If Cleishbotham's introduction tells us how the narrative entered the commercial marketplace, Pattieson's introduction tells us how the narrative was initially recovered from obscurity by conversing with those who travel off the beaten track or those who adhere to local tradition. ${ }^{12}$ His process of discovering the tale of Old Mortality educates readers that to reclaim obscure historical narratives, one must recognize that the process of transmission involves oral as well as print culture and objects as well as subjects.

Pattieson's introduction to Old Mortality begins with a meditation on what John Durham Peters calls "time-binding media," that is, monuments "such as statuary or architecture, [that] are durable and 'bind' distinct moments across great spans of time."13 In one of Pattieson's favorite haunts in the village of Gandercleugh, there is a little cemetery that contains some monuments erected in honor of Covenanters who fell in battle. While Pattieson initially observes that "those who sleep beneath [these monuments] are only connected with us by the reflection, that they have once been what we now are," his succeeding descriptions make clear that one may gain access to the buried through textual inscriptions $(O, 27)$. Despite the state of decay, these monuments still function as texts that offer information about those whom they memorialize. The monuments of the "doughty knight" and the "nameless bishop" bear various signs-such as armorial bearings, miters, and pastoral staff-whose values are verified by "tradition" $(O, 27)$. But there is yet another monument that signifies nothing of status, has no sculptured ornaments, and shows an inscription that consists simply of "rude prose, and ruder rhyme" $(O, 27)$. This tombstone, which belongs to "the class of persecuted Presbyterians who afforded a melancholy subject for history in the times of Charles II and his successor," is referred to merely as a "stone," as opposed to the "monument" of the knight or the "tomb" of the bishop $(O, 27)$. The stone and its inscription may both be humble, but "the history of those who sleep beneath them" can still be "read" on this solid text $(O, 27)$.

While this passage seems to confirm the time-binding nature of monuments as media, this role of monuments is immediately prob- 
lematized as it becomes clear that history is not quite dead, that it still has relevance to those still alive. Pattieson does not need to decode obscure inscriptions, since "the peasantry" continue to reverence these relics as memorials of "victims of prelacy," as well as emblems of their faith and principles $(O, 28)$. By pointing back to the memory of the deceased, the religious faith of the Covenanters lives on from generation to generation: "when they point [the tombstones] out to their sons, and narrate the fate of the sufferers, [they] usually conclude, by exhorting them to be ready, should times call for it, to resist to the death in the cause of civil and religious liberty, like their brave forefathers" $(O, 28)$. Monuments work as material counterparts to the narratives that are passed on from father to son and from generation to generation. While a visitor from afar may gather very little history from these monuments, the local peasants have many stories in store regarding those very monuments that seem to say so little to outsiders. Monuments are valuable not because they function as time-binding media that tell stories of their own, but because they remind people to tell and retell the stories they already know.

This symbiotic relationship between monuments and stories is exemplified in the title figure of Old Mortality. The featured historical narrative, Pattieson tells us, comes from the titular character, an itinerant who has devoted his life to visiting the numerous monuments of Covenanters who fell under the persecution of government. He "regulated his circuit so as annually to visit the graves of the unfortunate Covenanters," and his visit involved "cleaning the moss from the grey stones, renewing with his chisel the half-defaced inscriptions, and repairing the emblems of death with which these simple monuments are usually adorned" $(O, 30)$. He considered this a "sacred duty" which also enabled him to renew "to the eyes of posterity the decaying emblems of the zeal and sufferings of their forefathers, and thereby trimming, as it were, the beacon-light which was to warn future generations to defend their religion even unto blood" $(O, 30-31)$. Old Mortality thus seems dedicated to the preservation of time-binding media, but readers find that it is Old Mortality's skill as a narrator, not the tombstones, that provides material for Pattieson's succeeding narrative. Pattieson emphasizes the almost novelistic nature of Old Mortality's communications when he describes how vivid his narratives are: "One would almost have supposed he must have been their contemporary, and have actually beheld the passages which he related, so much had he identified his feelings and opinions with theirs, and so much had his narratives the circumstantiality of an eye-witness" $(O, 32$, emphasis 
added)..$^{14}$ But Old Mortality was not an eyewitness to the events he narrates; he was able to gather these narratives through his annual circulation through Scotland. As an itinerant figure, Old Mortality is at once a collector and a distributor, who is "profuse in the communication of all the minute information which he had collected concerning [the Covenanters], their wars, and their wanderings" $(O, 32)$. Old Mortality's storytelling ability supplements the silent textual status of monuments, while his narrative itself becomes enriched as he gathers "minute information" from others.

Old Mortality circulates stories so as to supplement the mere presence of texts and transmits historical memory from one generation to another. But his model of circulation is distinct from the kind of circulation that informs Cleishbotham of "the ways and works of the present generation." Indeed, Old Mortality neither extends the reaches of the stories he tells nor ensures that the stories of Covenanters will hereafter become part of a more general national history. The distinction that Régis Debray draws between communication and transmission helps us understand what is at stake in Old Mortality's activities. For Old Mortality, storytelling is not simply a matter of producing and disseminating information, or what Debray calls "communication." Old Mortality's storytelling is a means of "transmission," which is distinct from communication in that its aim is to ensure the survival of beliefs that are important to his particular cultural group. Old Mortality's lone struggle to renew "to the eyes of posterity the decaying emblems of the zeal and sufferings of their forefathers" thus makes him a part of "people establishing membership in a group ... and to coded procedures signaling that group's distinction from others," as Debray puts it. ${ }^{15}$ The memory of Covenanters, unsanctioned either by antiquarians or by the nation at large, resides obstinately within the small compass of local peasants scattered across the country, institutionalized as history only in the memory of those who follow an anti-institutional religious sect. Old Mortality's stories as well as the tombstones whose inscriptions he renews transmit cultural memory among the peasants, but they matter to these peasants only because they are already part of their culture. This group, which includes Old Mortality himself as well as the peasantry to whom Pattieson refers earlier in the passage, distinguishes itself through shared historical narratives, even from other cultures within Scotland and within the locality of the village of Gandercleugh. Old Mortality's work, Pattieson supposes, was inspired through religious enthusiasm in the first place; it is that very religious motivation that leads him to seek shelter from fellow Covenanters, to 
listen to their stories, and to propagate them in turn. Old Mortality perpetuates historical narratives for the Covenanters, and reaffirms their faith, community, and shared history. Old Mortality's narratives are thus confined to a closed circuit-one in which audiences and narrators are already initiated into a consensual understanding of the sufferings of their ancestors.

Scott's novel attempts to break this circuit and to put into national circulation what, for the Covenanters, is the stuff of tradition. Old Mortality circulates among various Covenanters' communities and freely exchanges stories with them so that no single person claims an authority over these stories; rather, these stories act as currency that implicitly sets the consensual standard of values within a community. By encouraging Old Mortality to narrate these stories to an outsider, Pattieson breaks a closed circuit and mediates the narratives' entrance into a wider realm of national print circulation-with some controversial results, as Ferris's account of the novel's reception shows. ${ }^{16}$ As Pattieson himself discloses, such mediation also distorts the narratives themselves. "[F]ar from adopting either [Old Mortality's] style, his opinions, or even his facts," he claims to "have endeavoured to correct or verify them from the most authentic sources of tradition, afforded by the representatives of either party" $(O, 34)$. After a long-winded introduction of Old Mortality, fleshing out the life and character of the itinerant storyteller, Pattieson buries that very embodied voice under a mass of historical documentation. He claims to balance Old Mortality's partial narrative by consulting the descendants of Loyalists, mainly through local lairds, their gamekeepers, and non-juring bishops. Old Mortality's partial perspective as a Dissenter is also supported, "much in the taste and spirit of the original," by "packmen or pedlars" as well as weavers and tailors who "may be considered as possessing a complete register of rural traditions" $(O, 34-35)$.

When Peter Pattieson thus explains his method of historical writing, he reveals how differently the historical writer and communal agents handle these narratives. The historical writer gathers narratives and arranges them so that the narratives are like so many objects put into relief to highlight the central image within a larger picture. Not so for the "representatives of either party," both Dissenters and Loyalists, whom Pattieson consults. For both parties, the narratives continue to be handed down like family heirlooms or other objects of value. Within such communities, each narrative, each rural tradition is valuable for its own sake. For Pattieson to lay claim to objectivity and to synthesize these narratives is for him to wrest the narratives 
from the original context, and to present them as curiosities within an antiquarian's cabinet of collections. If history writing is about collecting narratives from various communities so as to eradicate partiality, it also involves "the reframing of objects within a world of attention and manipulation of context." 17 What Susan Stewart claims to be the nature of collecting objects may illustrate the threat that Pattieson's historical method poses to the local community: "Like other forms of art, [the collection's] function is not the restoration of context of origin but rather the creation of a new context, a context standing in a metaphorical, rather than a contiguous, relation to the world of everyday life." ${ }^{18}$ Most disturbing to those to whom the narratives originally belonged, the collection presents "a world which . . . has banished repetition and achieved authority."19

\section{INSIDES AND OUTSIDES}

When James Buzard characterizes Scott's turn to novel writing as a self-conscious shift towards an authoethnographic model of writing, he gives us another vocabulary for discussing the dilemma of representing communal history that Scott, Cleishbotham, and Pattieson all encounter in varying degrees and forms. "Jedediah Cleishbotham and the other avatars Scott employs in his fiction," Buzard argues, "imply that they can apprehend and salute a 'Scottish culture' entire only from a position 'outside' or 'above' any particular locality within Scotland or any mentality belonging to one of that nation's religious or political factions - whose bloody conflicts have constituted much of Scottish history." ${ }^{20}$ The discontents that Scott's representations of history provoke arise from the fact that the narrator positions himself as an outsider, who presumes to "have endeavoured to correct or verify" Old Mortality's anecdotes. This position of the outsider is even more strongly claimed by Cleishbotham in the introduction to The Heart of Midlothian: "I . . c claim a privilege to write and speak of both parties with impartiality. For, $\mathrm{O}$ ye powers of logic! when the Prelatists and Presbyterians of old times went together by the ears in this unlucky country, my ancestor . . . was one of the people called Quakers, and suffered severe handling from either side" $(H, 11)$. Buzard urges us to acknowledge how Scott constructs an outside vantage point toward Scottish (and particularly Highland) culture, marketing his Scottish novels "within the framework of United Kingdom internal colonialism." ${ }^{21}$ Cleishbotham not only corroborates Buzard's argument, but also adds a tongue-in-cheek element to it by praising the "powers of 
logic" that help him create a position outside what is represented in the novel. Cleishbotham's invocation prompts us to consider further how the position of the "outside" is created - not only in geo-political space, but also in the space of writing.

The narrative framework of Old Mortality that I have been discussing demonstrates Scott's attempt to incorporate what lies "outside" of a narrative within the body of the text itself. By detailing the conveyerbelt-like process through which the story is handed from one person to another, Scott portrays the friction that occurs at each stage of narrative transmission; Pattieson recontextualizes Old Mortality's narrative by consulting the descendants of Loyalists, and Cleishbotham introduces Pattieson's tale with various caveats and marks of disapproval. These additional layers of narratives accumulate as sediment that tells the history and transmutations of the story, and seem to indicate that there is no smooth process that enables local, communal narratives to enter into national circulation without additions, distortions, or recontextualizations. Is it possible for communal and individual histories to enter the realm of national circulation and of the ever-expanding print market without losing their authenticity? What does such a transition entail? And how might a writer of historical novels like Scott conceive of his own agency when performing such a task?

The concluding pages of Old Mortality, together with the introductory frame of The Heart of Midlothian, provide some clues that help us to begin answering these questions. Scott famously begins Waverley and Ivanhoe with introductions that explain the principles of writing a historical narrative, focusing on issues of representing unfamiliar manners of past historical eras. But in the framing narratives of these two novels in Tales of My Landlord, Scott shifts his focus away from issues of representation and more towards those of mediation as he describes what we might call the infrastructure of the Romantic reading public-from the mail-coaches that deliver new periodical publications to assumptions about genre that underpin Romantic readers' encounters with the novel. However, in describing these mechanisms that sustain the kind of print-based imagined community that Anderson theorizes, Scott by no means claims a central position within a predominantly English reading public — and hence outside the provincial vantage point of an internally colonized Scotland. Rather, Scott suggests that both the material and the conceptual infrastructure of the nation perpetuate their own closed circuit of communication in ways that exclude the circulation and preservation of local, historical narratives. By contrasting his own work with others that participate 
in reading institutions such as the circulating library and periodical journals, Scott claims the position of a mediator between local and national circulation by staking out a position that lies not only outside of Scotland, but also outside of the increasing array of hegemonizing English cultural institutions.

The circulating library appears as the foremost example of an institution that trains readers to expect certain formal elements in a novel. A conversation between Pattieson and Miss Buskbody in the concluding frame of Old Mortality underscores how Scott's own work both satisfies and defies expectations raised by the circulating library. Miss Martha Buskbody is "a young lady who has carried on the profession of mantua-making at Gandercelugh and in the neighborhood, with great success, for about forty years" $(O, 455)$. In addition to supplying consumer goods, she is herself an avid consumer of fictional texts-from the circulating library. "Knowing her taste for narratives of this description," Pattieson states, "I requested her to look over the loose sheets the morning before I waited on her, and enlighten me by the experience which she must have acquired in reading through the whole stock of three circulating libraries, in Gandercleugh and the two next market towns" $(O, 455)$. Pattieson is particularly interested in consulting her about the ending to his narrative, in which he "had determined to wave the task of a concluding chapter, leaving to the reader's imagination the arrangements which must necessarily take place after Lord Evandale's death" $(O, 455)$. Pattieson's novel ends by portraying Henry Morton reunited with his beloved over the dead body of Lord Evandale, who had just been killed in a fray. Lord Evandale was on the verge of marriage with Edith Bellenden, who had been obliged to him for both protection and sustenance after the events that had ended in Morton's exile from his homeland. Lord Evandale's death, just at the moment of Morton's return, is at once an ending and a beginning; while his death signifies the end of one series of events, it also suggests the beginning of the reconciliation and eventual marriage between the two lovers by absolving Edith of her engagement to him. This ending, for Pattieson, has the recommendation of convenience. However, he is concerned that "precedents are wanting for a practice which might be found convenient both to readers and compilers" $(O$, 455). And he is right. Miss Buskbody cannot understand the suggestive ending that Pattieson substitutes for a conventional one. Like a habitual novel-reader, she presses Pattieson to provide satisfactory knowledge concerning the fate of every character. For Miss Buskbody, it is incumbent upon Pattieson to "redeem this gross error by telling 
us all about the marriage of Morton and Edith, and what became of the other personages of the story, from Lady Margaret down to Goose-Gibbie" $(O, 456)$.

While the inclusion of this conversation demonstrates Scott's familiarity with genre conventions, the fact that Pattieson's narrative conclusion fails to satisfy Miss Buskbody suggests that Pattieson's narrative is distinct from other novels. Miss Buskbody calls Pattieson's narrative experiment a "gross error" because her reading habits have already confirmed her idea of what a novel should be and how it should end. Pattieson's historical tale is regarded by this reader alongside Eliza Haywood's Jemmy and Jenny Jessamy and Henry Mackenzie's Julia de Roubigné - the former, a novel that Scott held up as an example of a bad novel, and the latter, a novel that Scott praised for its depth of feeling. ${ }^{22}$ Such an indiscriminate pairing of texts only confirms the readers' impression that Miss Buskbody is a questionable authority. Her gender, moreover, confirms the contemporary opinion that "women, especially impressionable young ladies, were [the circulating libraries'] main customers," as William St. Clair attests. ${ }^{23}$ So far from gaining authority from having read "the whole stock of three circulating libraries," such a reading habit shows that Miss Buskbody is a promiscuous reader who prefers "formulaic" reading material provided by "producers trying to commodify the texts textually as well as materially by implying that they were broadly similar, within quite narrow limits, both in subject matter and in the ideologies they advocated." ${ }^{24}$ As an avid reader of three circulating libraries, then, Miss Buskbody is assessing Pattieson's work based not so much on judgment and wide-ranging information, but based on the narrow, perhaps ill-formed, literary standards that were institutionalized by the circulating library.

Even beyond the gender-coded institution of the circulating library, novels were still considered to work "within quite narrow limits," as the next installment of Tales of My Landlord demonstrates. The Heart of Midlothian picks up where Old Mortality left off, focusing on a heroine whose father had settled into a modest agricultural life after experiencing the Covenanters' wars. The story focuses on Jeanie Deans's heroic journey to London to obtain pardon for her sister who had been found guilty of child murder. In the introductory frame of this novel, Scott stages a discussion between Pattieson and two Edinburgh lawyers about the Heart of Midlothian, the architecture of the Edinburgh prison that looms over the first half of the novel. Hardie, one of the lawyers, begins the discussion by mentioning that the prison is to be demolished, and that it should have its "Last Speech, Dying 
Confession, and Dying Words" just like the criminals it has contained $(H, 20)$. The lawyers suggest the publication of the "Causes Célèbres of Scotland" $(H, 22)$, claiming that the narratives culled from "State Trials, or in the Books of Adjournal" will produce narratives in which "you read new pages of the human heart, and turns of fortune far beyond what the boldest novelist ever attempted to produce from the coinage of his brain" $(H, 21-22)$. Hardie chooses to publish this narrative in a form reminiscent of criminal biographies, because he does not want them to resemble novels that are manufactured reproductions like coins and perpetuate their own signifying system without necessarily reflecting reality. Hardie is forced to choose between the two genres, since the source of his narratives - the State Trials and the Books of Adjournal-are hardly appealing to the general public, and are likely fated to remain in the lawyers' bookcases. Given the choice between novels and criminal biographies, Hardie considers criminal biography as the more appropriate vehicle for transmitting the narratives associated with the prison, because that genre will better distinguish the factual basis of the narratives: "The true thing," he states, "will triumph over the brightest inventions of the most ardent imagination" ( $H, 22)$. The differences between the "true thing" and fiction are differentiated by the way that fiction falls into a cycle of conventions, since it is difficult for authors to "hit upon characters or incidents which have not been used again and again, until they are familiar to the eye of the reader" $(H, 22)$. Hardie considers fiction as a product of economic circulation, a manifestation of how the print market recycles the same conventions over and over again. The print market does not just produce novels; it also reproduces them.

Scott thus describes how mainstream novels are trapped within conventions and boundaries imposed by society, just as much as obscure, local narratives remain in their confined circle as I have discussed earlier. This parallel is most vividly captured when he traces the origin of the story of Jeanie Deans, which is associated with the Heart of Midlothian. The Edinburgh prison physically contains a restricted society and encloses within its boundaries a narrative community. Economic theorists conventionally used the metaphor of the circulation of blood to describe the circulation of wealth throughout the nation, but the "Heart" of Midlothian does not pump blood to a larger body; it is an isolated body politic, whose economy extends no further than the prison walls. ${ }^{25}$ The Edinburgh Tolbooth has an internal economy that circulates money, goods, and narratives. Not only is the prison "a world within itself" that "has its own business, griefs, and joys, particular to 
that circle," it also has an isolated system of economic hierarchy so that "there are degrees of wealth and poverty among them" $(H, 20)$. Parallel to this monetary economy exists a narrative one, confined to those who live within its walls: "Jails, like other places, have their ancient traditions, known only to the inhabitants, and handed down from one set of the melancholy lodgers to the next who occupy their cells" $(H, 26)$. The narrative transmission in the Heart of Midlothian remains within the physical confines set by the prison walls, in a way that dramatizes the confined transmission of narrative among Covenanters in Old Mortality.

Scott contrasts this isolated community of the Heart of Midlothian with a nationwide information economy that has been expanding rapidly over the past generation. The opening chapter to The Heart of Midlothian begins by illustrating the transportation infrastructure that connects the village of Gandercleugh to the rest of Scotland and Great Britain. The vehicles that pass through the village enable "the rapid conveyance of intelligence and communication betwixt one part of Scotland and another." The slow but safe conveyances in the form of cumbersome stage coaches have been replaced by lighter, speedier vehicles, so that "mail-coach races against mail-coach, and high-flyer against high-flyer, through the most remote districts of Britain" $(H$, 13). This infrastructure of communication that characterizes modern Scotland, however, by no means works to fully integrate isolated, local communities within its network. Rather, such a network reinforces its own image of a centralized system of uninterrupted circulation, one that subordinates rather than incorporates local communities. Like the image of the post office that Mary Favret describes, rapid conveyances "figured a general restructuring of society in the nineteenth century, a restructuring that squeezed the irregularities of correspondence out of the public sphere. ${ }^{\prime 26}$ It creates readers who, like Pattieson, expect "by the coach a new number of an interesting periodical publication" that enables them to participate in the reading public $(H, 14)$. But that public is far different from the public sphere that Jürgen Habermas envisions as an arena of exchange for rational conversation. ${ }^{27}$ The reading public that Pattieson participates in is located along a one-way street, not because conversation is discouraged, but because communication occurs so quickly. The coaches deliver the new periodical publications so rapidly that there is no time for mutual exchange- the coach guard would "[skim] forth for [Pattieson's] grasp the expected packet, without the carriage checking its course for an instant" (H, 15, emphasis added). It is perhaps counterintuitive to imagine that rapid circulation hindered 
rather than facilitated the exchange of ideas. In a technological society, we are conditioned to think that reliable, smooth, and fast access to one another through sound technological infrastructure enables good communication..$^{28} \mathrm{Scott}$, however, implies that rapid circulation merely produces passive consumers who are perpetually exposed to objects of mass production-like Miss Buskbody.

If developments in the transportation system extended the reach of a print-based imagined community so as to further consolidate a British national culture, it would seem difficult to step outside of its influence and to turn one's eyes towards forgotten authentic narratives of local, isolated communities that do not circulate in the print market. It is telling, then, that Scott stages the introduction of the tale of The Heart of Midlothian as an accident-an accident that creates a narrative space "outside" the national system of circulation. Pattieson never receives his periodical publication, and instead witnesses the overturn of the carriage. After safely extricating "the insides by a sort of summary and Caesarean process of delivery" from "the womb of the leathern conveniency," Pattieson proceeds to rescue the "outsides" who were tossed into the river from their elevated situation $(H, 15-16)$. The outsides - two Edinburgh lawyers and a man recently released from the Heart of Midlothian-who are refused conveyance because of their wet garments, resort to the village inn with Pattieson, where they share with him various legal anecdotes that become, under Pattieson's pen, the narrative of The Heart of Midlothian. Contrary to the expectation raised by the metaphor of birth and reproduction in this passage, the "insides" who were "delivered" from the carriage move on to the next stage of their journey without contributing to the production of Pattieson's narrative. ${ }^{29}$ Instead, it is the outsides, who have been disabled from continuing the previous mode of travel, who communicate the incidents regarding the Edinburgh Tolbooth, signifying the break between the kind of "communication" that would have conveyed to Pattieson "a new periodical publication" and the narrative that follows.

\section{CIRCULATION AND THE INSTITUTION OF THE NOVEL}

If this opening scene of The Heart of Midlothian demonstrates how an obscure, local tale might enter the broader realm of circulation accidentally, the character of the Duke of Argyle within the central narrative helps to show how a qualified agent can facilitate such a process. Later in the novel, Jeanie Deans walks all the way to London 
to plead for her sister's life. She cannot do so, however, without the help of a qualified mediator, and she asks the Duke of Argyle for assistance. The narrator labors to emphasize how the Duke of Argyle is a peculiarly suitable mediator for Jeanie's story. He is familiar with the conventions of the English court, but his private virtues and public position both seem to guarantee that he will not sacrifice the truth of Jeanie's story and the authenticity of Jeanie's voice to the conventions of mainstream discourse. Not only is he "free from the ordinary vices of statesmen, falsehood, namely, and dissimulation," but he is also able to "[soar] above the petty distinctions of faction," thus maintaining a position of independence, respectability, and popularity $(H, 344)$. In describing the Duke of Argyle, Scott is doing more than just portraying an honored historical figure of Scotland. He is also portraying an author figure, not of those romances that are "coined" from authors' brains, but of "the true thing" that "will triumph over the brightest inventions of the most ardent imagination." Jeanie may be able to tell her story "with a pathos which was at once simple and solemn" $(H$, 370), in "tones so affecting, that, like the notes of some of her native songs, provincial vulgarity was lost in pathos" $(H, 366)$. But it is the Duke of Argyle who stages Jeanie's appearance and ensures that she is heard at all.

Argyle's presentation of Jeanie mirrors Scott's representation of the origins of his own narratives; they both originate in obscure localities of Scotland, and they both require a rather unconventional series of mediations to gain an audience. Most importantly, they are both able to touch the audience's heart because of their authenticity - a literary version of what Walter Benjamin calls "the aura of the work of art." 30 Benjamin's ideas about what makes a work of art unique are uncannily similar to the way Scott situates his own narratives in Tales of My Landlord novels; a work of art has an aura when it has a "unique existence at the place where it happens to be" and "[ $t$ ]his unique existence of the work of art determined the history to which it was subject throughout the time of its existence."31 By identifying the origins of narratives in the close confines of the Heart of Midlothian or within the community of Covenanters, Scott renders their existence unique. Unlike Benjamin, however, who believed that "[b]y making many reproductions, [the technique of reproduction] substitutes a plurality of copies for a unique existence," Scott frequently makes attempts to reconcile the "unique existence" of his stories with the problems of economic circulation such as reproduction and mass marketing. ${ }^{32}$

I shall conclude by exploring how Scott negotiates this conflict be- 
tween economic circulation and authenticity. Scott participates in and builds upon a broader cultural awareness that the infrastructure of the print market impacts how readers think about the value of a printed text. I argue that writers and readers of the time started to theorize the idea of "best sellers" in a way that prefigures the institutionalization of best sellers as a commercial term and mechanism. The print culture of Scott's generation was characterized by a burgeoning awareness of how the print public sphere worked to create literary value in ways that departed from classical conceptions of literary value held by previous generations. Scott builds upon these fluctuating conceptions of literary value to construct an idea of authenticity that works as an alternative to Benjamin's - one that is based on a dialectical relationship between space-binding media and time-binding media, between circulation and stability, and between reproductions and originals.

Unsurprisingly, it is Scott himself who works as the best case study for observing the effect of rapid circulation in the print culture of his generation. St. Clair asserts that "[d]uring the romantic period, the 'Author of Waverley' sold more novels than all the other novelists of the time put together." 33 Such statistical analysis gives us a vivid sense of the popularity of the "Author of Waverley" in comparison to other novelists of the age. Implicit in these statistics is the assumption that copies of Waverley were consumed more quickly than other novels, since rapid sales are a precondition for the achievement of a higher cumulative sales statistic within a given time frame. If statistical analysis helps to establish the rapid circulation of the Waverley Novels as a fact, the two following review articles help to illustrate the effects of rapid textual consumption. According to The British Critic, Waverley circulated throughout the nation so quickly that it turned the relationship between reader and reviewer topsy-turvy: "So rapid is the circulation of those works, to which the public attention has been by anticipation directed, that it is our province rather to confirm or correct a judgment already formed, than to direct it to a new and undiscovered object." 34 The situation hardly improves as Scott publishes more and more novels. In October 1821, The Quarterly Review published a review of Rob Roy (1817), The Heart of Midlothian (1818), The Bride of Lammermoor and A Legend of Montrose (1819), Ivanhoe (1819), The Monastery (1820), and Kenilworth (1821), in which the reviewer confesses his own powerlessness as a critic. Similar to the British Critic, the language of the Quarterly Review article reveals a confused but nascent recognition that when texts circulate faster, assessment of literary value shifts away from the hands of select critics to an anonymous mass of readers. 
Indeed, the Quarterly can hardly pretend to accomplish much of what it considers to be the objectives for a standard review article. It cannot "draw the public attention to works, which are bought, and borrowed, and stolen, and begged for, a hundred times more than our dry and perishable pages;" it cannot presume to provide feedback and criticism to an author whose pen outstrips the pace of periodical reviewers; it cannot guide public opinion that had already been formed so that "our praise or blame cannot well be heard among the voices of the whole nation." 35 The rapid circulation of the Waverley Novels, the Quarterly suggests, contributes to the forming of a "voice" in which the "whole nation" is united so that the critical acumen of the reviewer, instead of guiding the public, follows it.

In describing the rapid circulation of the Waverley Novels, these review articles analyze the effects of consumer democracy on literary texts that will come to manifest itself later on in the form of "bestsellers." The word "best seller," according to the OED, first came into use in the late-nineteenth-century United States. ${ }^{36}$ The best-seller list can be traced back to its embryonic state in a London-based monthly periodical titled The Bookman, established in October 1891 by William Robertson Nicoll (1851-1923). The periodical catered to those involved in the business of book selling, publishing, and printing. Early issues of The Bookman included a section titled "Behind a Bookseller's Counter" that contained ruminations on the current state of the book market and offered analysis of trends that would allow the bookseller to help his customers who might be overwhelmed by the variety of reading options. This section eventually developed into a section titled "Monthly Report of the Wholesale Book Trade" that included a prototype of the best-seller list. ${ }^{37}$ While these early versions of the best-seller list were geared towards booksellers rather than readers, they already served the same function that best-seller lists perform today. As Laura Miller puts it, "best-seller lists are powerful marketing tools that book professionals use to sell more books"- the more powerful because "[ $t]$ hey appear to be straightforward devices that objectively provide us with interesting information about the actions of culture consumers." ${ }^{38}$ Best-seller lists, of course, are not without their detractors. Yet the very fact that one cannot completely ignore the best-seller list testifies to the condition of the modern reader-as long as literary texts appear in the context of a commercial culture, it is difficult to distinguish the text that is valuable because of its intrinsic qualities, from the text that is valuable because of its popularity.

The writer of the aforementioned Quarterly Review article en- 
counters this very problem of distinguishing intrinsic literary value from that conferred by popularity and resolves it by concluding that current trends themselves are worthy of being recorded as history. The Quarterly declares that "One of our duties is, to give a literary history of the times we live in-to tell those who follow us what were the subjects and the writers which chiefly engaged the attention of our contemporaries." ${ }^{39}$ He participates in the recording-if not the construction—of literary history through his "perishable pages." ${ }^{40}$ If contemporary readers cannot benefit from the publication of such book reviews, perhaps "those who follow us" can. ${ }^{41}$ Just as Tales of My Landlord records how Jeanie Deans and Old Mortality both circulated at one point in history and memorializes the value of such circulation in the form of fiction, the Quarterly invests value into the object by recording the very fact that such a thing did indeed circulate at one point in history.

For many writers and readers of the previous century, however, the Quarterly's willingness to use the rapid circulation of Waverley Novels as evidence of their value would have been puzzling, if not outrageous. For much of the eighteenth century, writers and readers were trying to reconcile themselves to both the quantity and frequency of print circulation. Their skepticism of circulation was often associated with the material form of the publications. While the larger folio volumes were considered stationary occupants of the library, lighter, speedier forms of distributing information such as periodicals and newspapers were regarded as ephemeral and less dignified. In a number of The Spectator, for instance, Joseph Addison illustrates this idea by representing how the degree of respect and dignity accorded to different forms of print translate into "Rank and Precedence" among authors:

I have observed that the Author of a Folio, in all Companies and Conversations, sets himself above the Author of a Quarto: the Author of a Quarto above the Author of an Octavo; and so on, by a gradual Descent and Subordination, to an Author in Twenty-Fours. . . The most Minute Pocket-Author hath beneath him the Writers of all Pamphlets, or Works that are only stitched. As for the Pamphleteer, he takes place of none but of the Authors of single Sheets, and of that Fraternity who publish their Labours on certain Days, or on every Day of the Week. ${ }^{42}$

While the order of books is dictated by relative size in a straightforward manner, Addison's manner of sorting the remaining publications is perhaps less so. The main criterion that distinguishes pamphlets from periodicals seems to be the minimal binding of "stitche[s]" or 
the lack thereof. But the final clause emphasizes the periodicity of the publication rather than its materiality; periodicals lack dignity not only because they are scantily dressed, but also because they get around a bit too much.

Later in the century, George Crabbe presents a similar conceit in verse, though the occupants of the lowest ranks reflect changes in print culture:

Lo! all in silence, all in order stand;

And mighty folios first, a lordly band,

Then quartos, their well-order'd ranks maintain,

And light octavos fill a spacious plain;

See yonder, ranged in more frequented rows,

A humbler band of duodecimos;

While undistinguish'd trifles swell the scene,

The last new play and fritter'd magazine. ${ }^{43}$

For Crabbe, the dignity of the different kinds of binding and print does not just hold a superficial resemblance to social class as it seems to do for Addison. The size of the book has a direct correlation with the dignity of its contents, and a reverse correlation with the amount of circulation. Hence, "in these times," the folio volumes remain "untouch'd, . . . / And slumber out their immortality," experiencing no circulation despite their contribution to the knowledge of "Our patient fathers." ${ }^{4}$ On the contrary, current readers seek "lighter labours" to such an extent that they are "Cloy'd with a folio-Number once a week." ${ }^{55}$ Crabbe's elegiac account of "The Library" reproaches modern readers who absorb information only through frequent consumption of small printed matter, in the form of "cuts and comments." ${ }^{46}$ Such a situation is particularly dire in Crabbe's view, since he hardly trusted these "number' $d$ " vehicles of information. ${ }^{47}$ He imagined that writers of periodicals merely wrote enough to satisfy the spatial and quantitative requirements imposed on periodicals, so as to "join / As many words as make an even line" and "As many lies as fill a row complete" and so on, until they filled the entire sheet. ${ }^{48}$

This does not mean that all widely and rapidly circulating texts had no authority and no value. Indeed, The Spectator, which was published daily excluding Sundays, managed to establish literary value at the time. As a writer of a daily paper, Mr. Spectator ranks lowest on the social scale of authors that he himself describes. He gains status among his fellow writers, not because his papers circulate more, but because his writing is transformed from a single-page periodical to 
bound volumes: "I never presumed to take Place of a Pamphleteer till my daily Papers were gathered into those two first Volumes, which have already appeared." ${ }^{49}$ Unlike the reviewers of Scott's novels, Addison does not to believe that circulation itself speaks to the value of the publication. Literary value, for Addison, comes with the sense of permanence represented by the materiality of the bound volume. Even for writers such as Samuel Johnson, who, like Addison, wrote periodical essays such as The Rambler and The Idler, the idea of literary value remained classical in the sense that it aimed to produce lasting fame that can continue to thrive in Parnassus like "oaks of towering height" and "laurels of eternal verdure. "50 An author who accomplishes such a feat, in Johnson's imagination, "writes upon general principles, or delivers universal truths," and "may hope to be often read . . . at all times and in every country, but he cannot expect it to be received with eagerness, or to spread with rapidity." ${ }^{.51}$ Writings that experience "quick circulation," on the other hand, are those that "take advantage of present incidents or characters which strongly interest the passions, and engage universal attention. ${ }^{.52}$ By necessity, works that experience "quick circulation" are not qualified to continue to occupy Parnassus after its season has passed. It is only the tombs that contain universal truths, according to Johnson, that endure to become literary classics.

Johnson's ideas about literary value did not disappear with the coming of the nineteenth century. But the distinction between enduring "universal truths" and writings that experience "quick circulation" that was so very clear to Johnson seems to become less so for Scott's readers, since the changing infrastructure of the print market exposed them generally to a more rapid circulation of texts. Scott captures this very ambivalence in The Heart of Midlothian by establishing Jeanie Deans in the valley of Roseneath, secluded from extended society and the forces of history, after she has made her remarkable journey to London; her temporary fame brought about by circulation seems to gain for her a permanent home. Likewise, the reviews of Scott's novels exemplify how the line becomes blurred between what is permanent and what is temporary, what transmits ideas and expressions of value through time and what transmits them through space. Thus, the reviews choose to reconcile the two by adopting a more historically attuned attitude generated at the intersection of a reading public and consumer democracy that values literary popularity for what it is-a historical record of trends.

Scott demonstrates how he participates in and builds upon this historicizing of literary trends in the editorial matter of Ballantyne's 
Novelist's Library. Along with other anthologies of novels compiled and published during the decades immediately before and after 1800 , Ballantyne's Novelist's Library gathered novels of previous generations and consolidated them in a standardized collection. While some anthologies focused on making these novels available to a wide variety of readers through cheap serial publication, Ballantyne's Novelist's Library provided a historical outlook on these novels through the prefatory material written by Sir Walter Scott. ${ }^{53}$ When we look into the contents of Ballantyne's Novelist's Library, and when we read Scott's biographical discussion of each author, we find that Scott by no means saw enduring value or universal truth in each and every novel. For instance, his discussion of Charles Johnstone's Chrysal makes explicit that he considers his work merely as a curious relic of a past generation. But he also makes clear that the novel's past popularity-the fact that it circulated and was read by many-is a sufficient reason for its inclusion in the library. ${ }^{54}$ The idea of the best seller, then, seems folded into the novel's history as it is being institutionalized during the Romantic period. When Homer Brown points out that various English novels of the eighteenth century "have now taken on a lasting solidity in these magnificent sets" of the Ballantyne's Novelist's Library, he emphasizes the anthology's kinship to tombs and monuments that work as time-binding media. ${ }^{55}$ The idea of "solidity" that is embodied in the materiality of the books thus echoes Johnson's and Crabbe's ideals of the enduring literary classic. And yet that enduring quality may be achieved not just through the intrinsic value of the novel, but also through its history of circulation. In the process of institutionalizing the novel, then, transmission through space ("quick circulation") and transmission through time ("lasting solidity") enter a sort of dialectic so that circulating texts are given a permanent place, so that they continue to circulate in posterity.

Novelistic canon-formation, then, seems to be a process that both presupposes and entails circulation and reproduction, leaving no room to accommodate Scott's "authentic" narratives that originate outside the realm of mass marketing. Or does it? Scott later suggests that it is worth sacrificing some degree of authenticity if that is what it takes for stories to be included in this process of cultural transmission. One may trace narratives to their unique origins later on, as long as they are preserved and transmitted in the first place. In the additional preface to The Heart of Midlothian that Scott wrote for the Magnum Opus edition in 1830, Scott reveals "that the information [that inspired the novel] was conveyed to him by a late amiable and ingenious lady," 
who communicated by letter a brief narrative about her acquaintance with a humble and obscure Scottish woman, Helen Walker $(H, 3)$. Her history is so remarkable that Scott's correspondent Mrs. Goldie "once proposed that a small monument should have been erected to commemorate so remarkable a character." "But," she proceeds, "I now prefer leaving it to you to perpetuate her memory in a more durable manner" $(H, 5)$. Scott's correspondent suggests that literary works are "more durable" than material mediums like monuments. Mrs. Goldie's assessment of the monument-like function of print proves partially true. Though Helen Walker became better known by the name of Jeanie Deans, her history was recovered in a way that it would not have been had it remained memorialized in a "small monument" in an obscure churchyard. As it turns out, Helen Walker's history is authenticated retroactively as her biographical information is recorded in the chronicles of local history-after the publication of The Heart of Midlothian. ${ }^{56}$ While Scott's novels may not, in fact, originate from a quiet cemetery in a hidden corner of Scotland where relics of the past generation will narrate to strangers the history of those who lie under stones with obscure inscriptions, they show that such scenes-and the authenticity that comes with it—may be constructed retroactively. Perhaps it is with such intention that Scott, at the end of his preface, assures Mrs. Goldie's daughter that he will honor Helen Walker's memory by erecting an actual monument in addition to the novel.

\section{Indiana University South Bend}

\section{NOTES}

I am very grateful to Deidre Lynch for her insightful feedback at various stages of this manuscript. I also wish to thank Mark Parker, my fellow panelist at the 2009 NASSR conference, for sharing with me his expert knowledge of book review conventions.

${ }^{1}$ Sir Walter Scott, The Heart of Midlothian, ed. Claire Lamont (Oxford: Oxford Univ. Press, 1999), 13. Hereafter abbreviated $H$ and cited parenthetically by page number.

${ }^{2}$ On the crucial role of periodicals in the literary and political milieu of the Romantic period, I have consulted Jon Klancher, The Making of English Reading Audiences 1790-1832 (Madison: Univ. of Wisconsin Press, 1987), and Kevin Gilmartin, Print Politics: The Press and Radical Opposition in Early Nineteenth-Century England (Cambridge: Cambridge Univ. Press, 2005).

${ }^{3}$ Benedict Anderson, Imagined Communities: Reflections on the Origin and Spread of Nationalism (London: Verso, 1991), 35. Mary Favret extensively discusses the role of mail-coaches in Romantic infrastructures of communication in Romantic Correspondence: Women, Politics, and the Fiction of Letters (Cambridge: Cambridge Univ. Press, 2005), 16-17. I am also influenced by James Chandler's discussions about how historical consciousness was heightened during the Romantic period in England in 1819: The Politics of Literary Culture and the Case of Romantic Historicism (Chicago: Univ. of Chicago Press, 1999), esp. 42-46. 
${ }^{4}$ See Ina Ferris, The Achievement of Literary Authority: Gender, History, and the Waverley Novels (Ithaca: Cornell Univ. Press, 1991), 137-60. See also Esther Schor, "Scott's Hebraic Historicism," in British Romanticism and the Jews: History, Culture, Literature, ed. Sheila A. Spector (New York: Palgrave Macmillan, 2002), 105-20.

${ }^{5}$ These accusations are not necessarily antagonistic but have been repeated frequently since the publication of Scott's novels. In 1825, William Hazlitt praises the Waverley Novels and characterizes them as cultural imports that are "brought us in ship-loads from the neighbourhood of Abbt's-ford" (Hazlitt, from The Spirit of the Age, in Scott: The Critical Heritage, ed. John O. Hayden [New York: Barnes and Noble, 1970], 283). More recently, James Buzard states that Scott "appears to have known himself to be fabricating to suit the touristic interests of English readers" (Disorienting Fiction: The Autoethnographic Work of Nineteenth-Century British Novels [Princeton: Princeton Univ. Press, 2005], 63-64). Harry Shaw articulates this question head-on and frames it from an Orientalist perspective in Narrating Reality: Austen, Scott, Eliot (Ithaca: Cornell Univ. Press, 1999), 168-75.

${ }^{6}$ Walter Scott, Old Mortality, ed. Jane Stevenson and Peter Davidson (Oxford: Oxford Univ. Press, 1999), 5, 6. Hereafter abbreviated $O$ and cited parenthetically by page number.

${ }^{7}$ On the term "fictions of social circulation," see Deidre Shauna Lynch, The Economy of Character: Novels, Market Culture, and the Business of Inner Meaning (Chicago: Chicago Univ. Press, 1998), 135-38.

${ }^{8}$ Henry Fielding, Tom Jones, ed. John Bender and Simon Stern (Oxford: Oxford Univ. Press, 1996), 648-49.

${ }^{9}$ Walter Scott, Waverley, ed. Claire Lamont (Oxford: Oxford Univ. Press), 5.

${ }^{10}$ Scott, Waverley, 5.

${ }^{11}$ William Wordsworth, The Prelude of 1805 in Thirteen Books, in The Prelude 1799, 1805, 1850, ed. Jonathan Wordsworth, M. H. Abrams, and Stephen Gill (New York: W. W. Norton, 1979), book 1, lines 174, 170, 172, 175-76.

${ }^{12}$ My reading of this sequence emphasizes the proximity of history while James Kerr argues that it helps place history at a safe distance. See Kerr, Fiction Against History: Scott as Storyteller (Cambridge: Cambridge Univ. Press, 1989), 40-44.

${ }^{13}$ John Durham Peters, Speaking into the Air: A History of the Idea of Communication (Chicago: Univ. of Chicago Press, 1999), 138. Peters contrasts "time-binding media" made of lasting material like stone with "space-binding media" such as paper and electricity that can travel quickly to cover wide geographical areas. Peters inherits this contrast from Harold Innis, who in Empire and Communications (Oxford: Clarendon Press, 1950) argues that empires sustain their dominion by creating a balance between the two kinds of media.

${ }^{14}$ Everett Zimmerman, in The Boundaries of Fiction: History and the EighteenthCentury British Novel (Ithaca: Cornell Univ. Press, 1996), claims that Old Mortality's reliance on rhetoric lessens his value as a historical witness (218). I contend that Old Mortality is not so much a historical witness as he is an agent of transmission.

${ }^{15}$ Régis Debray, Transmitting Culture, trans. Eric Rauth (New York: Columbia Univ. Press, 2000), 4.

${ }^{16}$ Ferris details how the publication of Old Mortality triggered a paper war between Scott and contemporary Covenanters such as Thomas McCrie and John Wilson Croker. They accused Scott of adopting a perspective that is partial to the persecutors who sided with the English government and of representing Covenanters unjustly by caricaturing their use of biblical language. Ferris focuses on how participants in this debate contend 
over the authority to represent the history of a particular religious group, while Schor provides detailed analysis of how Scott's representation of the Covenanters is inflected by an anti-Semitic rhetorical tradition. See Ferris, 137-60, and Schor, 105-20.

${ }^{17}$ Susan Stewart, On Longing: Narratives of the Miniature, the Gigantic, the Souvenir, the Collection (Durham: Duke Univ. Press, 1993), 152.

${ }^{18}$ Stewart, 152.

${ }^{19}$ Stewart, 152.

${ }^{20}$ Buzard, 64.

${ }^{21}$ Buzard, 64.

${ }^{22}$ In his autobiographical fragment, Scott unfavorably compares the types of novels exemplified by Eliza Haywood's The History of Jemmy and Jenny Jessamy with those by Henry Mackenzie, the author of Julia de Roubigné: "The whole Jemmy and Jenny Jessamy tribe I abhorred, and it required the art of Burney, or the feeling of Mackenzie, to fix my attention on a domestic tale" (J. G. Lockhart, Memoirs of Sir Walter Scott, 5 vol. [London: Macmillan, 1915], 1:35).

${ }^{23}$ William St. Clair, The Reading Nation in the Romantic Period (Cambridge: Cambridge Univ. Press, 2004), 242. For further detail on circulating libraries, see Barbara M. Benedict, "Sensibility by the Numbers: Austen's Work as Regency Popular Fiction," in Janeites: Austen's Disciples and Devotees, ed. Deidre Lynch (Princeton: Princeton Univ. Press, 2000), 63-86.

${ }^{24}$ St Clair, $244-45$.

${ }^{25}$ On the nation as a body, see, for instance, Thomas Hobbes, Leviathan, ed. C. B. Macpherson (London: Penguin, 1985), 300. Evan Gottlieb also considers the word "heart" as having a deceptively unstable significance in the novel in "To be at Once Another and the Same': Walter Scott and the End(s) of Sympathetic Britishness," Studies in Romanticism 43 (2004): 187-207.

${ }^{26}$ Favret, 203.

${ }^{27}$ See Jürgen Habermas, The Structural Transformation of the Public Sphere: An Inquiry into a Category of Bourgeois Society, trans. Thomas Burger (Cambridge: MIT Press, 1999), 31-43.

${ }^{28}$ See Peters, 5-6.

${ }^{29}$ Andrea Henderson claims that this scene exemplifies how the novel uses "an image of birth to render reproductive an energy that might otherwise be disruptive" in Romantic Identities: Varieties of Subjectivity, 1774-1830 (Cambridge: Cambridge Univ. Press, 2006), 134. While I agree that this scene shows how disruption can be turned productive, my reading emphasizes how the novel strives to dissociate itself from acts of reproduction.

${ }^{30}$ Walter Benjamin, "The Work of Art in the Age of Mechanical Reproduction," in Illuminations, ed. Hannah Arendt, trans. Harry Zohn (New York: Harcourt Brace Jovanovich, 1968), 221.

${ }^{31}$ Benjamin, 220.

${ }^{32}$ Benjamin, 221.

${ }^{33}$ St. Clair, 221.

${ }^{34}$ Unsigned review of Waverley by Walter Scott, British Critic, August 1814, in Scott: The Critical Heritage, 67.

35 "Nassau Senior surveys the novels, Quarterly Review," in Scott: The Critical Heritage, 215.

${ }^{36}$ Oxford English Dictionary, 2nd ed., s.v. "best" (first example of "best seller" 1889 in Kansas Times \& Star). 
${ }^{37}$ For a brief history of the best-seller list as well as the main critical issues surrounding it, see Laura J. Miller, "The Best-Seller List as Marketing Tool and Historical Fiction" in Book History 3 (2000): 286-304.

${ }^{38}$ Miller, 286-87.

${ }^{39}$ Scott: The Critical Heritage, 215.

${ }^{40}$ Scott: The Critical Heritage, 215.

${ }^{41}$ Scott: The Critical Heritage, 215.

${ }^{42}$ Joseph Addison, The Spectator no. 529, in The Spectator Vol. 4 of 4 (London: J. M. Dent \& Sons, 1946), 168.

${ }^{43}$ George Crabbe, "The Library," in Poems Vol. 1 of 3, ed. Adolphus William Ward (Cambridge: Cambridge Univ. Press, 1905), lines 127-34.

${ }^{44}$ Crabbe, "The Library," lines 157, 157-8, 179.

${ }^{45}$ Crabbe, "The Library," lines 189, 190.

${ }^{46}$ Crabbe, "The Library," line 191.

${ }^{47}$ Crabbe, "The Library," line 192.

${ }^{48}$ George Crabbe, "The Newspaper," in Poems Vol. 1 of 3, lines 219-20, 221.

${ }^{49}$ Addison, 168.

${ }^{50}$ Samuel Johnson, Selected Essays from the Rambler, Adventurer, and Idler, ed. W. J. Bate (New Haven: Yale Univ. Press, 1968), 168.

${ }^{51}$ Johnson, 327.

52 Johnson, 168.

${ }^{53}$ See St. Clair, 534-37; Homer Obed Brown, Institutions of the English Novel: From Defoe to Scott (Philadelphia: Univ. of Pennsylvania Press, 1997), 179-85.

${ }^{54}$ Scott claims that Johnstone is only interesting "as the author of what has been termed the Scandalous Chronicle of the time" and gives little merit to his work. But he also allows that "the time in which he lived called for such an unsparing and uncompromising censor" (Sir Walter Scott on Novelists and Fiction, ed. Ioan Williams [New York: Barnes and Noble, 1968], 131, 132;, see also131-37).

${ }^{55}$ Brown, 183.

${ }^{56}$ Ann Rigney discusses how the novel becomes the source for historical accounts of Helen Walker and argues that the novel works as a peculiar vehicle for transmitting cultural memory in "Portable Monuments: Literature, Cultural Memory, and the Case of Jeanie Deans," Poetics Today 25 (2004): 361-96. 